\title{
DOI 10.35381/cm.v7i2.544
}

\section{EI Derecho Constitucional en Ecuador y su interacción directa con la protección de los ciudadanos}

\section{Constitutional Law in Ecuador and its direct interaction with the protection of citizens}

\author{
Orlando Iván Ronquillo-Riera \\ uq.orlandoronquillo@uniandes.edu.ec \\ Universidad Regional Autónoma de los Andes, Quevedo \\ Ecuador \\ https://orcid.org/0000-0001-6020-7255 \\ María José Bermello-González \\ mariajose.bermello@gmail.com \\ Universidad Regional Autónoma de los Andes, Quevedo \\ Ecuador \\ https://orcid.org/0000-0002-2344-3117 \\ Edwin Rolando Moreno-Lascano \\ edwin.rolando.moreno@hotmail.com \\ Universidad Regional Autónoma de los Andes, Quevedo \\ Ecuador \\ https://orcid.org/0000-0002-6026-1806 \\ Elcia Beatriz Villacres-Paredes \\ beateiz741020@hotmail.com \\ Universidad Regional Autónoma de los Andes, Quevedo \\ Ecuador \\ https://orcid.org/0000-0002-9509-5422
}

Recibido: 10 de junio de 2021

Aprobado: 01 de septiembre de 2021 
Orlando Iván Ronquillo-Riera; María José Bermello-González; Edwin Rolando Moreno-Lascano;

Elcia Beatriz Villacres-Paredes

\title{
RESUMEN
}

En la presente investigación se planteó como objetivo general analizar jurídicamente el Derecho Constitucional en Ecuador y su interacción directa en la protección de los ciudadanos. Dicho estudio es descriptivo documental con diseño bibliográfico, el enfoque fue cuantitativa, ya que se utilizaron técnicas de exploración documental jurídica para fundamentar el tema de estudio. Desde la perspectiva del análisis sintético permitió el estudio de la información recopilada, se empleó como instrumento de investigación la ficha o guía de análisis documental, artículos científicos en revista arbitradas y el cuerpo de leyes de la República. Es necesario destacar el papel protagónico del Estado en garantizar los derechos constitucionales de sus ciudadanos mediante las herramientas jurídicas. Se concluye que el derecho constitucional en el Ecuador fortalece la diferencia entre los derechos fundamentales y constitucionales, con el objeto de instituir en la sociedad la intervención, colaboración y participación ciudadana como elemento de poder del ciudadano.

Descriptores: Derecho constitucional; protección social; imperio de la ley. (Palabras tomadas del Tesauro UNESCO).

\begin{abstract}
The general objective of this research was to legally analyze Constitutional Law in Ecuador and its direct interaction in the protection of citizens. This study is descriptive documentary with bibliographic design, the approach was quantitative, since legal documentary exploration techniques were used to substantiate the study topic. From the perspective of synthetic analysis, it allowed the study of the information collected, the document analysis file or guide, scientific articles in peer-reviewed journals and the body of laws of the Republic were used as a research instrument. It is necessary to highlight the leading role of the State in guaranteeing the constitutional rights of its citizens through legal tools. It is concluded that constitutional law in Ecuador strengthens the difference between fundamental and constitutional rights, in order to institute citizen intervention, collaboration and participation in society as an element of citizen power.
\end{abstract}

Descriptors: Constitutional right; social protection; rule of law. (Words taken from the UNESCO Thesaurus). 
Orlando Iván Ronquillo-Riera; María José Bermello-González; Edwin Rolando Moreno-Lascano; Elcia Beatriz Villacres-Paredes

\section{INTRODUCCIÓN}

El Estado reconoce y garantiza al cuidado derecho ciudadano en la Constitución de la República. Desde la perspectiva de los derechos, y deberes. Sin embargo, en distintos países existen escándalos por actos improcedentes en materia constitucional, debilitando la confianza de los ciudadanos hacia sus leyes y derechos constitucionales; situación no ajena al contexto ecuatoriano, lo que hace que se comiencen a establecer medidas dentro de su organismo a fin de combatir los hechos de corrupción desde las organizaciones jurídicas y otras instituciones del Estado. (Castro Pizarro, Masache Romero y Duran Ocampo, 2007).

En tal sentido un protagonista de suma importancia es el abogado, cuyo deber fundamental, como partícipe en la función pública de la Administración de Justicia, es cooperar con ella: asesorando, conciliando y defendiendo los intereses que le sean confiados. (Merlano Sierra, 2010, p.98), además de los profesionales del derecho en su conjunto jueces, magistrados entre otros, al respecto Castro Pizarro, et al., (2019) plantean que, se necesita de una mejor selección y capacitación de los servidores públicos, administrativos y profesionales de justicia; así como de una eficiente divulgación dirigida a la población sobre las normas y derechos, para así promover la aplicación y cumplimiento de las políticas públicas y el ordenamiento jurídico, en aras de eliminar los actos inconstitucionales e infractores de la Ley. Por otro lado, las juezas y jueces tienen la circunstancia de modernizar sus conocimientos y aprender nuevas formas de interpretación y de solución de casos, que no solo valen para el derecho constitucional sino para mejor solucionar incluso en el derecho civil o penal.

En este mismo orden de ideas la Constitución de la República del Ecuador (2008) indica: en su artículo 82.- El derecho a la seguridad jurídica se fundamenta en el respeto a la Constitución y en la existencia de normas jurídicas previas, claras, públicas y aplicadas por las autoridades competentes. 
En consecuencia, es importante fortalecer los derechos constitucionales desde una teoría necesaria del contenido constitucional, evitando ambigüedades de origen y de vacíos jurídicos, interpretados y comentados según la conveniencia de quien tiene el poder (López Hidalgo, 2019).

Bajo esta tesitura la Ley Orgánica de Garantías Jurisdiccionales y Control Constitucional (2009) establece lo siguiente:

\section{Cuadro 1.}

Contenido de la ley.

\begin{tabular}{|l|l|}
\hline \multicolumn{1}{|c|}{ Artículos } & \multicolumn{1}{|c|}{ Disposición } \\
\hline Artículo. 1.- Objeto y finalidad de la & $\begin{array}{l}\text { Esta ley tiene por objeto regular la } \\
\text { jurisdicción constitucional, con el fin de } \\
\text { garantizar jurisdiccionalmente los } \\
\text { derechos reconocidos en la la } \\
\text { Constitución y en los instrumentos } \\
\text { internacionales de derechos humanos y } \\
\text { de la naturaleza; yarantizar la eficacia } \\
\text { y la supremacía constitucional. }\end{array}$ \\
\hline Artículo. 2.- Principios de la justicia \\
constitucional & $\begin{array}{l}\text { Además de los principios establecidos } \\
\text { en la Constitución, se tendrán en cuenta }\end{array}$ \\
& $\begin{array}{l}\text { los siguientes principios generales para } \\
\text { resolver las causas que se sometan a } \\
\text { su conocimiento: } \\
\text { 1. Principio de aplicación más favorable } \\
\text { a los derechos. Si hay varias normas o } \\
\text { interpretaciones aplicables a un caso } \\
\text { concreto, se debe elegir la que más } \\
\text { proteja los derechos de la persona. } \\
\text { 2.Optimización de los principios } \\
\text { constitucionales. La creación, } \\
\text { interpretación y aplicación del derecho } \\
\text { deberá orientarse hacia el cumplimiento } \\
\text { y optimización de los principios }\end{array}$ \\
\hline
\end{tabular}




\begin{tabular}{|c|c|}
\hline & $\begin{array}{l}\text { constitucionales. } \\
\text { 3.Obligatoriedad del precedente } \\
\text { constitucional. Los parámetros } \\
\text { interpretativos de la Constitución fijados } \\
\text { por la Corte Constitucional en los casos } \\
\text { sometidos a su conocimiento tienen } \\
\text { fuerza vinculante. La Corte podrá } \\
\text { alejarse de sus precedentes de forma } \\
\text { explícita y argumentada garantizando } \\
\text { la progresividad de los derechos y la } \\
\text { vigencia del estado constitucional de } \\
\text { derechos y justicia. } \\
\text { 4.Obligatoriedad de administrar justicia } \\
\text { constitucional. No se puede suspender } \\
\text { ni denegar la administración de justicia } \\
\text { por contradicciones entre normas, } \\
\text { oscuridad o falta de norma jurídica. }\end{array}$ \\
\hline $\begin{array}{l}\text { Artículo. 3.- Métodos y reglas de } \\
\text { interpretación constitucional }\end{array}$ & $\begin{array}{l}\text { Las normas constitucionales se } \\
\text { interpretarán en el sentido que más se } \\
\text { ajuste a la Constitución en su } \\
\text { integralidad, en caso de duda, se } \\
\text { interpretará en el sentido que más } \\
\text { favorezca a la plena vigencia de los } \\
\text { derechos reconocidos en la } \\
\text { Constitución y que mejor respete la } \\
\text { voluntad del constituyente. }\end{array}$ \\
\hline Artículo. 6.-Finalidad de las garantías & $\begin{array}{l}\text { Las garantías jurisdiccionales tienen } \\
\text { como finalidad la protección eficaz e } \\
\text { inmediata de los derechos reconocidos } \\
\text { en la Constitución y en los instrumentos } \\
\text { internacionales de derechos humanos, } \\
\text { la declaración de la violación de uno o } \\
\text { varios derechos, así como la reparación } \\
\text { integral de los daños causados por su } \\
\text { violación. } \\
\text { Las medidas cautelares tienen como } \\
\text { finalidad prevenir, impedir o interrumpir } \\
\text { la violación de un derecho. }\end{array}$ \\
\hline
\end{tabular}

Elaboración: Los autores. 
Orlando Iván Ronquillo-Riera; María José Bermello-González; Edwin Rolando Moreno-Lascano;

Elcia Beatriz Villacres-Paredes

A juzgar por la elaboración de la ley, el Estado ecuatoriano mantiene su convicción institucional en la protección de los ciudadanos, además de sus deberes como ciudadanos. Al respecto Ávila Santamaría, R. (2012) plantea que, en consecuencia:

Las acciones judiciales siempre han estado diseñadas para proteger derechos. Tradicionalmente los jueces y juezas han sido entrenados, en las universidades y en la práctica, para aplicar el derecho sustantivo y seguir los procedimientos. En el derecho sustantivo la gran matriz ha sido el Código Civil y el Código Penal, y en el derecho adjetivo los códigos de procedimiento civil y penal. (p.2015)

Luego de los descrito se planteó como objetivo de la presente investigación analizar jurídicamente el Derecho Constitucional en Ecuador y su interacción directa en la protección de los ciudadanos.

\section{METODOLOGÍA}

El estudio es una investigación descriptiva documental con diseño bibliográfico, el enfoque fue cuantitativa, ya que se utilizaron técnicas de exploración documental jurídica para fundamentar el Derecho Constitucional en el Ecuador y su interacción directa con la protección de los ciudadanos. Desde la perspectiva del análisis sintético permitió el estudio de la información recopilada, se empleó como instrumento de investigación la ficha o guía de análisis documental, lo que contribuyó a extraer las ideas y contrastarlas. Así como investigaciones de artículos científicos en revista arbitradas y el cuerpo de leyes de la Republica. 


\section{RESULTADOS}

En consecuencia, se presenta a continuación los resultados obtenidos de la investigación documental:

Cuadro 2.

\section{Derechos Constitucionales.}

\begin{tabular}{|c|c|}
\hline Ley/Código Orqánico & Artículos \\
\hline $\begin{array}{l}\text { Constitución de la República de Ecuador } \\
\text { (2008) }\end{array}$ & $\begin{array}{l}\text { Artículo. 69.- Para proteger los derechos de } \\
\text { las personas integrantes de la familia: } 1 \text {. Se } \\
\text { promoverá la maternidad y paternidad } \\
\text { responsables; la madre y el padre estarán } \\
\text { obligados al cuidado, crianza, educación, } \\
\text { alimentación, desarrollo integral y protección } \\
\text { de los derechos de sus hijas e hijos, en } \\
\text { particular cuando se encuentren separados } \\
\text { de ellos por cualquier motivo.... }\end{array}$ \\
\hline Código de la Niñez y Adolescencia (2003) & $\begin{array}{l}\text { Artículo. 11.- El interés superior del niño. - El } \\
\text { interés superior del niño es un principio que } \\
\text { está orientado a satisfacer el ejercicio efectivo } \\
\text { del conjunto de los derechos de los niños, } \\
\text { niñas y adolescentes; e impone a todas las } \\
\text { autoridades administrativas y judiciales y a las } \\
\text { instituciones públicas y privadas, el deber de } \\
\text { ajustar sus decisiones y acciones para su } \\
\text { cumplimiento. } \\
\text { Artículo 9.- Función básica de la familia. La ley } \\
\text { reconoce y protege a la familia como el } \\
\text { espacio natural y fundamental para el } \\
\text { desarrollo integral del niño, niña y } \\
\text { adolescente. } \\
\text { Artículo } 22 .- \text { Derecho a tener una familia y a la } \\
\text { convivencia familiar. Los niños, niñas y } \\
\text { adolescentes tienen derecho a vivir y } \\
\text { desarrollarse en su familia biológica. El } \\
\text { Estado, la sociedad y la familia deben adoptar }\end{array}$ \\
\hline
\end{tabular}




\begin{tabular}{|c|c|}
\hline & $\begin{array}{l}\text { prioritariamente medidas apropiadas que } \\
\text { permitan su permanencia en dicha familia. }\end{array}$ \\
\hline $\begin{array}{l}\text { Ley para prevenir y erradicar la violencia } \\
\text { contra las mujeres (2018) }\end{array}$ & $\begin{array}{l}\text { Artículo 4.- Definiciones. Para efectos de } \\
\text { aplicación de la presente Ley, a continuación, } \\
\text { se definen los siguientes términos: } \\
\text { 1.Violencia de género contra las mujeres. - } \\
\text { Cualquier acción o conducta basada en su } \\
\text { género que cause o no muerte, daño y/o } \\
\text { sufrimiento físico, sexual, psicológico, } \\
\text { económico o patrimonial, gineco-obstétrico a } \\
\text { las mujeres, tanto en el ámbito público como } \\
\text { privado. } \\
\text { 2. Daño. - Es el perjuicio causado a una } \\
\text { persona como consecuencia de un evento } \\
\text { determinado. En este caso el daño implica la } \\
\text { lesión, menoscabo, mengua, agravio, de un } \\
\text { derecho de la víctima. } \\
\text { 3. Estereotipos de género. - Es toda } \\
\text { preconcepción de atributos y características } \\
\text { poseídas o papeles que son o deberian ser } \\
\text { ejecutados por hombres y mujeres, } \\
\text { respectivamente. } \\
\text { 4. Víctimas. - Se considera a la mujer y/o } \\
\text { demás miembros integrantes del núcleo } \\
\text { familiar que sufran violencia o afectación } \\
\text { ejecutada por un miembro de la familia. } \\
5 \text {. Persona agresora. - Quien comete una } \\
\text { acción u omisión que implique cualquier forma } \\
\text { de violencia contra las mujeres. } \\
\text { 6. Ámbito público. - Espacio en el que se } \\
\text { desarrollan las tareas políticas, productivas de } \\
\text { la sociedad y de servicios remunerados, } \\
\text { vinculadas a la gestión de lo público. } \\
\text { 7. Ámbito privado. - Espacio en el que se } \\
\text { desarrollan las tareas reproductivas; de la } \\
\text { economía del cuidado, remuneradas o no, } \\
\text { vinculadas a la familia y a lo doméstico. } \\
\text { 8. Relaciones de poder. - Acciones, omisiones } \\
\text { y prácticas sociales, políticas, económicas, } \\
\text { culturales o simbólicas que determinan la } \\
\text { imposición de la voluntad de una persona o } \\
\text { grupo por sobre la de } \\
\text { otro, desde una relación de dominación o } \\
\text { subordinación, que implica la distribución }\end{array}$ \\
\hline
\end{tabular}




\begin{tabular}{|c|c|}
\hline & $\begin{array}{l}\text { asimétrica del poder y el acceso y control a los } \\
\text { recursos materiales e inmateriales entre } \\
\text { hombres y mujeres. }\end{array}$ \\
\hline Código Orgánico Integral Penal (2014) & $\begin{array}{l}\text { Artículo 140.- Asesinato. - La persona que } \\
\text { mate a otra será sancionada con pena } \\
\text { privativa de libertad de veintidós a veintiséis } \\
\text { años, si concurre alguna de las } \\
\text { siguientes circunstancias: } \\
\text { 1. A sabiendas, la persona infractora ha dado } \\
\text { muerte a su ascendiente, descendiente, } \\
\text { cónyuge, conviviente, hermana o hermano. } \\
\text { 2. Colocar a la víctima en situación de } \\
\text { indefensión, inferioridad o aprovecharse de } \\
\text { esta situación. }\end{array}$ \\
\hline $\begin{array}{l}\text { Ley Orgánica de Garantías Jurisdiccionales y } \\
\text { Control Constitucional (2009) }\end{array}$ & $\begin{array}{l}\text { Artículo 39.- Objeto. - La acción de protección } \\
\text { tendrá por objeto el amparo directo y eficaz de } \\
\text { los derechos reconocidos en la Constitución y } \\
\text { tratados internacionales sobre derechos } \\
\text { humanos, que no estén amparados por las } \\
\text { acciones de hábeas corpus, acceso a la } \\
\text { información pública, hábeas data, por } \\
\text { incumplimiento, extraordinaria de protección y } \\
\text { extraordinaria de protección contra decisiones } \\
\text { de la justicia indígena. } \\
\text { Artículo 40.- Requisitos. - La acción de } \\
\text { protección se podrá presentar cuando } \\
\text { concurran los siguientes requisitos: } \\
\text { 1. Violación de un derecho constitucional; } \\
\text { 2. Acción u omisión de autoridad pública o de } \\
\text { un particular de conformidad con el artículo } \\
\text { siguiente; y, } \\
\text { 3. Inexistencia de otro mecanismo de defensa } \\
\text { judicial adecuado y eficaz para proteger el } \\
\text { derecho violado. } \\
\text { Artículo } 41 .- \text { Procedencia y legitimación } \\
\text { pasiva. La acción de protección procede } \\
\text { contra: } \\
\text { 1. Todo acto u omisión de una autoridad } \\
\text { pública no judicial que viole o haya violado los } \\
\text { derechos, que menoscabe, disminuya o anule } \\
\text { su goce o ejercicio. } \\
\text { 2. Toda política pública, nacional o local, que } \\
\text { conlleve la privación del goce o ejercicio de los } \\
\text { derechos y garantías. }\end{array}$ \\
\hline
\end{tabular}




\begin{tabular}{|c|c|}
\hline & $\begin{array}{l}\text { 3. Todo acto u omisión del prestador de } \\
\text { servicio público que viole los derechos y } \\
\text { garantías. } \\
\text { 4. Todo acto u omisión de personas naturales } \\
\text { o jurídicas del sector privado, cuando ocurra } \\
\text { al menos una de las siguientes circunstancias: } \\
\text { a) Presten servicios públicos impropios o de } \\
\text { interés público; } \\
\text { b) Presten servicios públicos por delegación o } \\
\text { concesión; } \\
\text { c) Provoque daño grave; } \\
\text { d) La persona afectada se encuentre en } \\
\text { estado de subordinación o indefensión frente } \\
\text { a un poder económico, social, cultural, } \\
\text { religioso o de cualquier otro tipo. } \\
5 \text {. Todo acto discriminatorio cometido por } \\
\text { cualquier persona. }\end{array}$ \\
\hline Código Orgánico de la Función Judicial (2015) & $\begin{array}{l}\text { Artículo. 23.- Principio de Tutela Judicial } \\
\text { Efectiva de los Derechos. - La Función } \\
\text { Judicial, por intermedio de las juezas y jueces, } \\
\text { tiene el deber fundamental de garantizar la } \\
\text { tutela judicial efectiva de los derechos } \\
\text { declarados en la Constitución y en los } \\
\text { instrumentos internacionales de derechos } \\
\text { humanos o establecidos en las leyes, cuando } \\
\text { sean reclamados por sus titulares o quienes } \\
\text { invoquen esa calidad, cualquiera sea la } \\
\text { materia, el derecho o la garantía exigido. } \\
\text { Deberán resolver siempre las pretensiones y } \\
\text { excepciones que hayan deducido los } \\
\text { litigantes sobre la única base de la } \\
\text { Constitución, los instrumentos internacionales } \\
\text { de derechos humanos, los instrumentos } \\
\text { internacionales ratificados por el Estado, la } \\
\text { ley, y los méritos del proceso. La } \\
\text { desestimación por vicios de forma únicamente } \\
\text { podrá producirse cuando los mismos hayan } \\
\text { ocasionado nulidad insanable o provocado } \\
\text { indefensión en el proceso. Para garantizar la } \\
\text { tutela judicial efectiva de los derechos, y evitar } \\
\text { que las reclamaciones queden sin decisión } \\
\text { sobre lo principal, por el reiterado } \\
\text { pronunciamiento de la falta de competencia } \\
\text { de las juezas y jueces que previnieron en el }\end{array}$ \\
\hline
\end{tabular}




\begin{tabular}{|l|l|}
\hline & $\begin{array}{l}\text { conocimiento en la situación permitida por la } \\
\text { ley, las juezas y jueces están obligados a } \\
\text { dictar fallo sin que les sea permitido excusarse } \\
\text { o inhibirse por no corresponderles. }\end{array}$ \\
\hline
\end{tabular}

Elaboración: Los autores.

Al observar los resultados obtenidos de la revisión documental, es necesario destacar el papel protagónico del Estado en garantizar los derechos constitucionales de sus ciudadanos mediante las herramientas jurídicas, algunas de ellas señaladas en el cuadro 2.

\section{CONCLUSIONES}

El Estado garantiza y reconoce a los ciudadanos sus derechos y deberes con el propósito de establecer una armonía de convivencia ciudadana dentro de los valores de respeto, colaboración, y buen vivir.

El derecho constitucional en el Ecuador fortalece la diferencia entre los derechos fundamentales y constitucionales, con el objeto de instituir en la sociedad la intervención, colaboración y participación ciudadana como elemento de poder ciudadano capaz de lograr su protagonismo en las políticas públicas plasmadas en la carta Magna, las normas, leyes, y se aplique de forma equilibrada con el objeto de mantener el equilibro social.

\section{REFERENCIAS CONSULTADAS}

Asamblea Nacional Constituyente de la República del Ecuador, (2008). Constitución de la República del Ecuador Montecristi. Registro Oficial 449 de 20-oct-2008. Recuperado de https://n9.cl/sia

Asamblea Nacional del Ecuador. (2015). Código Orgánico de la Función Judicial. Ley 0 Registro Oficial Suplemento 544 de 09-mar.-2009. Recuperado de: https://n9.cl/wm4o 
Orlando Iván Ronquillo-Riera; María José Bermello-González; Edwin Rolando Moreno-Lascano; Elcia Beatriz Villacres-Paredes

Asamblea Nacional (2009). Ley Orgánica de Garantías Jurisdiccionales y Control Constitucional. Segundo Suplemento del Registro Oficial No.52, 22 de octubre 2009. Recuperado de: https://n9.cl/kqdip

Asamblea Nacional República del Ecuador (2018). Ley para prevenir y erradicar la violencia contra las mujeres. Ley 0 Registro Oficial Suplemento 175 de 05-feb.2018 Estado: Vigente. Recuperado de: https://n9.cl/h7v9h

Ávila Santamaría, R. (2012) Los derechos y sus garantías Ensayos críticos. Centro de Estudios y Difusión del Derecho Constitucional. Quito Ecuador.

Código Orgánico Integral Penal. (2014). Quito. CEP.

Congreso Nacional. (2003). Código de la niñez y adolescencia. Quito.

Castro Pizarro, J., Masache Romero, C. y Duran Ocampo, A. (2007) La aplicación del Derecho Público en el Ecuador Universidad $y$ Sociedad,11(4),350-360. http://orcid.org/0000-0003-0111-0669

Castro Pizarro, J, Masache Romero, C, y Durán campo, A. (2019). La aplicación del Derecho Público en el Ecuador. Revista Universidad y Sociedad, 11(4), 350-360

López Hidalgo, S. (2019). Configuración de los derechos fundamentales y su contenido esencial en el constitucionalismo ecuatoriano. Cuestiones constitucionales, (41), 221-247. https://doi.org/10.22201/iij.24484881e.2019.41.13946

Merlano-Sierra, J. (2010) La responsabilidad jurídica de abogados y administradores de justicia en el Derecho colombiano. Revista de Derecho. 33,96-120.Reuperado de: http://www.scielo.org.co/pdf/dere/n33/n33a05.pdf

(C2021 por los autores. Este artículo es de acceso abierto y distribuido según los términos y condiciones de la licencia Creative Commons Atribución-NoComercial-Compartirlgual 4.0 Internacional (CC BY-NC-SA 4.0)

(https://creativecommons.org/licenses/by-nc-sa/4.0/ 